\title{
Calcemic Responses to Photic and Pharmacologic Manipulation of Serum Melatonin
}

\author{
DAVID O. HAKANSON, ROBERT PENNY, AND WILLIAM H. BERGSTROM \\ Departments of Pediatrics, SUNY Health Science Center, Syracuse New York 13210 and USC Medical Center, \\ Los Angeles, California
}

\begin{abstract}
Phototherapy of newborn rats (NBR) resulted in a decrease in serum calcium and melatonin levels. Transcranial light penetrance in NBR increased with wavelength. Below $640 \mathrm{~nm}$ (penetrance $=6.9 \%$ ), no hypocalcemic effect could be demonstrated. Shielding the occiput of NBR prevented a decrease in serum calcium during phototherapy and substantially reduced the decrease in melatonin found in unshielded NBR. Intraperitoneal injection of propranolol, an inhibitor of melatonin synthesis, caused a decrease in serum calcium in shaded NBR. In contrast, when melatonin was injected with propranolol a decrease in serum calcium did not occur. Additionally, intraperitoneal isoproterenol before phototherapy protected against a decrease in serum calcium. These data are consistent with an hypothesis that a decrease in serum calcium during phototherapy results from transcranial photic inhibition of melatonin synthesis. (Pediatr Res 22: 414-416, 1987)
\end{abstract}

\section{Abbreviations}

NBR, newborn rats

IP, intraperitoneal

CAP, occipital shield

Serum calcium concentration decreases in human infants and NBR exposed to white light at the energy level used in phototherapy for hyperbilirubinemia $\left(5 \mu \mathrm{W} / \mathrm{cm}^{2} / \mathrm{nm}\right)(1,2)$. This effect is not seen when the occiput is shielded (2), when blue light is used $(2,3)$, or, in NBR, when exogenous melatonin is given before light exposure (2). Transcranial illumination of the pineal inhibits melatonin synthesis (4), and we have hypothesized that the resultant decrease in serum melatonin might be responsible for the hypocalcemic effect of phototherapy (2).

If this hypothesis is valid, it should be possible to demonstrate: 1) a relationship between the transcranial penetrance of light and its effect on calcium, 2) decreased serum melatonin concurrent with decreased serum calcium during phototherapy, and 3) changes in serum calcium after pharmacologic manipulation of melatonin synthesis.

We determined transcranial light penetrance and serum calcium levels after exposure to light at $510 \mathrm{~nm}$ (blue), $545 \mathrm{~nm}$ (green), and $640 \mathrm{~nm}$ (yellow). We also measured serum melatonin and calcium in NBR during phototherapy with and without CAP; controls were shaded littermates.

Received November 4, 1986; accepted May 8, 1987.

Address for correspondence and reprint requests David O. Hakanson, M.D., Department of Pediatrics, Division of Neonatology, SUNY Health Science Center at Syracuse, 750 East Adams Street, Syracuse, NY 13210.

Supported in part by the Professional Staff Association of the Los Angeles County-University of Southern California Medical Center.
Axelrod (8) has reported that melatonin synthesis in the pineal is inhibited by propranolol and stimulated by isoproterenol; this effect is mediated by regulation of $n$-acetyltransferase activity and is independent of photic stimuli. We therefore measured serum calcium concentration after propranolol injection in shaded NBR and during phototherapy in NBR given IP isoproterenol prior to light exposure in order to determine the response of serum calcium to pharmacologic alteration of melatonin synthesis.

\section{MATERIALS AND METHODS}

In studies previously reported (2), we found that the decrease in serum calcium concentration during phototherapy in NBR was independent of age between $6 \mathrm{~h}$ and 14 days, was maximal $(-0.8 \mathrm{mg} / \mathrm{dl})$ after $1 \mathrm{~h}$ of light exposure, and persisted without change for at least $6 \mathrm{~h}$ (the maximum duration of the experiments cited). The present experiments were therefore kept within these age and time limits.

Since the size of the animals ( $10 \mathrm{~g}$ at 4 days; $17 \mathrm{~g}$ at 10 days) precluded serial blood sampling, it was necessary to evaluate the effect of light by comparing the serum calcium concentration of NBR exposed to light with that of littermates separated from their mothers but kept shaded. The effect of maternal deprivation was assessed in three litters of 18- to 24-h old rats. Half of each litter was left with the mother; half was kept for $3 \mathrm{~h}$ in shaded plastic trays under the light source. Serum calcium in the 12 separated rats was $7.9 \pm 0.10 \mathrm{mg} / \mathrm{dl}$; in 11 littermates left with their mothers it was also $7.9 \pm 0.10 \mathrm{mg} / \mathrm{dl}( \pm \mathrm{SE})$. We concluded that separation and tray confinement had no effect on serum calcium within $3 \mathrm{~h}$ and that differences between littermates kept in shaded and illuminated trays could be attributed to light.

Rats aged 4-10 days were confined in shallow plastic trays and exposed to white fluorescent lights delivering $5.3 \mu \mathrm{W} / \mathrm{cm}^{2} / \mathrm{nm}$ at $425-475 \mathrm{~nm}$ as determined by an Air Shields PR III radiometer. Littermate controls were kept in adjacent shaded trays. At the intervals indicated below, blood was collected by decapitation under terminal ether anesthesia. Calcium was measured by EDTA titration (5) and melatonin by immunoassay (6); in our laboratories, the intraassay coefficients of variation were $3.0 \%$ for calcium and $8.0 \%$ for melatonin. Since this method required $1 \mathrm{ml}$ of serum (7), blood samples were pooled during collection and each melatonin data point represents four NBR.

The effect of varying wavelengths of incident light was investigated by interposing gelatin filters between the white light source and the plastic confining trays. Peak light transmission for each filter was determined with a Gilford spectrophotometer. Transcranial penetrance was measured by interposing freshly prepared segments of NBR cranium including scalp, calvarium, and dura between a light source of defined wavelength and an appropriate sensor. This was done by mounting cranial segments in a Gilford spectrophotometer and recording light transmission at $20-\mathrm{nm}$ intervals between 330 and $730 \mathrm{~nm}$.

Melatonin was purchased from Sigma Chemical Company (St. 
Louis, MO), dissolved in $1 \%$ ethanol in saline, and given by IP injection at the doses indicated below; controls received an equal volume of vehicle. Occipital shields, when used, consisted of black silk or India ink; both devices prevented detectable light transmission.

Serum calcium levels were determined in shaded NBR after IP propranolol $(2.5 \mu \mathrm{g} / \mathrm{g})$ with and without exogenous melatonin $(15 \mu \mathrm{g} / \mathrm{g})$. Also, serum calcium levels were determined in NBR after IP isoproterenol $(2.0 \mu \mathrm{g} / \mathrm{g})$ followed by phototherapy; controls received an equal volume of vehicle.

The significance of differences between group means was evaluated by Student's $t$ test.

\section{RESULTS}

Table 1 shows that transcranial light penetrance increased with wavelength. Serum calcium was not affected by blue or green light; the first decrease $(0.6 \mathrm{mg} / \mathrm{dl}$ ) was seen at $640 \mathrm{~nm}$ (yellow light) when transmission was $6.9 \%$.

Figure 1 shows the changes in serum melatonin and calcium concentrations after light exposure with and without occipital shielding. Serum melatonin and calcium decreased during phototherapy ( $p<0.01$ versus shaded controls). CAPs prevented the change in serum calcium, and serum melatonin in the CAP group was not significantly different after phototherapy from that found in shaded NBR.

Figure 2 indicates that serum calcium concentration in shaded NBR was significantly lower $2 \mathrm{~h}$ after IP propranolol than in

Table 1. Transcranial penetrance versus hypocalcemic effect*

\begin{tabular}{|c|c|c|c|c|c|c|c|}
\hline \multicolumn{2}{|c|}{ Filter } & \multirow{2}{*}{$\begin{array}{c}\% \\
\text { cranial } \\
\text { penetrance }\end{array}$} & \multirow[b]{2}{*}{$(n)$} & \multicolumn{4}{|c|}{ Serum calcium $(\mathrm{mg} / \mathrm{dl})$} \\
\hline Colo & $\mathrm{nm}$ & & & Shaded & $(n)$ & Pho & $(n)$ \\
\hline Blu & 510 & $4.2 \pm 0.1$ & (7) & 8 & (2 & & ) \\
\hline Gr & 545 & & (7) & 11 & (8) & & (12) \\
\hline Yellow & 640 & $6.9 \pm 0.1$ & (7) & $9.2 \pm 0.12$ & $(22)$ & $8.6 \pm 0.18$ & $(17) \dagger$ \\
\hline
\end{tabular}

* Transmittance peak for each filter is shown in $\mathrm{nm}$. Cranial penetrance at each wavelength is the percent transmission (mean of seven samples) of cranial discs read at the wavelength noted (see text). Phototherapy $=$ values after $3 \mathrm{~h}$ at each wavelength; shaded $=$ littermate controls.

$\dagger=p<0.01$, shade versus photo.

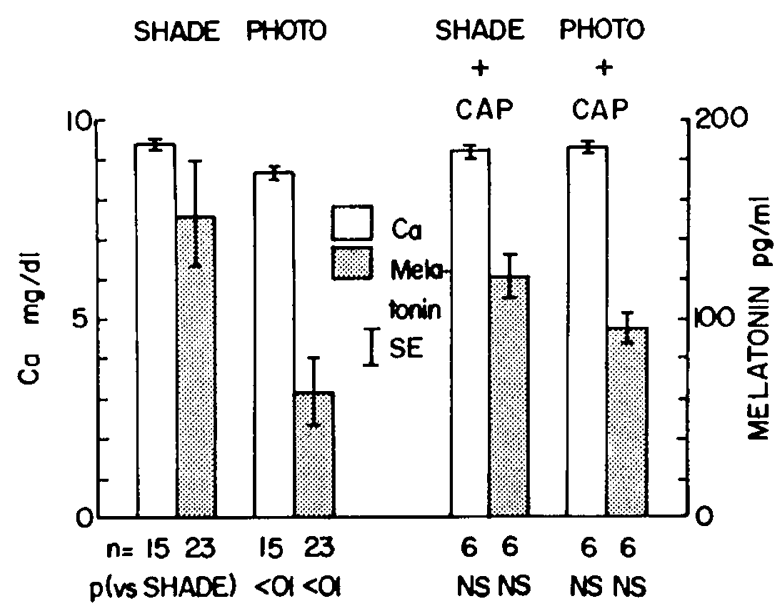

Fig. 1. Effects of phototherapy $(3 \mathrm{~h})$ on serum calcium and melatonin concentrations. When the occiput was shielded (CAP), serum calcium concentration did not change and serum melatonin after phototherapy was not significantly different from that of shaded controls. $n=$ number of determinations; each determination was performed on the pooled serum of four rats.

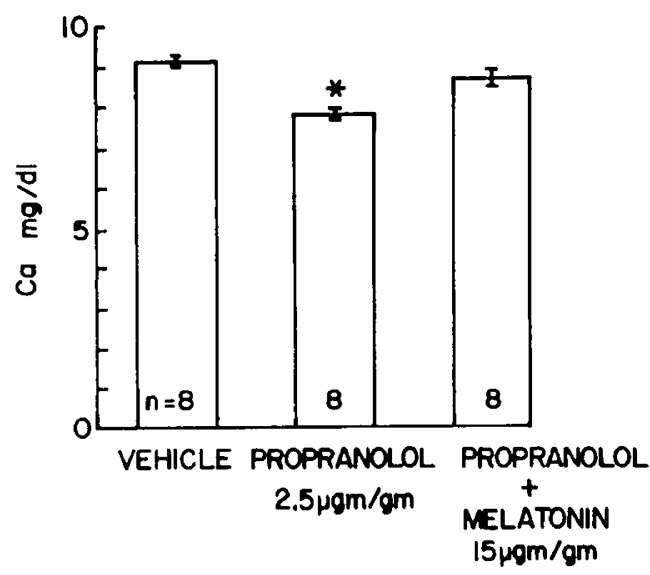

Fig. 2. Effect of intraperitoneal propranolol (with and without melatonin) on serum calcium levels in shaded NBR. Time from injection to sampling $=2 \mathrm{~h} .{ }^{*} p<0.01$ versus other two groups.

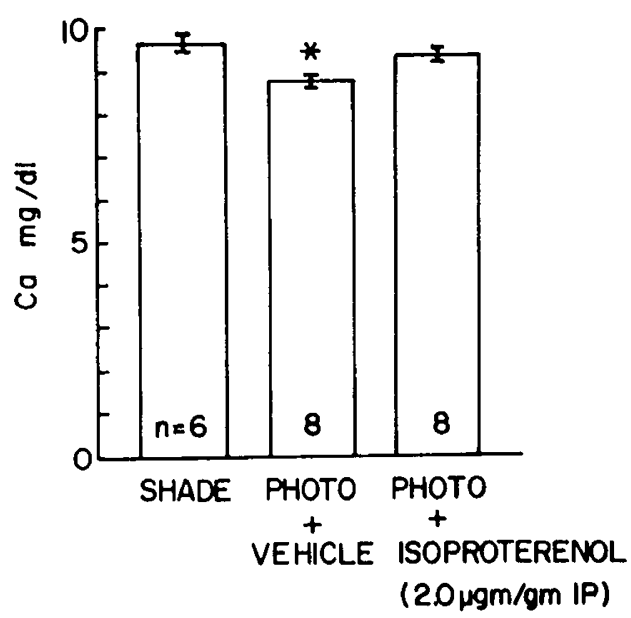

Fig. 3. Serum calcium concentration after $3 \mathrm{~h}$ of phototherapy; isoproterenol or vehicle $\left(^{*}\right)$ was given immediately before light exposure. Shaded controls also received vehicle $3 \mathrm{~h}$ before sampling. Serum calcium was lower $(8.8 \pm 0.08 \mathrm{mg} / \mathrm{dl})$ in vehicle-injected phototherapy NBR than in shaded controls $(9.7 \pm 0.07 \mathrm{mg} / \mathrm{dl})$ or isoproterenol-treated phototherapy NBR $(9.4 \pm 0.08 \mathrm{mg} / \mathrm{dl}) ; p<0.001$.

vehicle-injected littermates and that simultaneous administration of melatonin prevented the hypocalcemic effect of propranolol.

When NBR were given IP isoproterenol $(2.0 \mu \mathrm{g} / \mathrm{g})$ before phototherapy (Fig. 3), the decrease in serum calcium compared to the mean for vehicle-injected shaded littermates was $0.3 \pm$ $0.08 \mathrm{mg} / \mathrm{dl}$. In vehicle-injected NBR, the decrease after phototherapy was $0.9 \pm 0.08 \mathrm{mg} / \mathrm{dl}$ compared to shaded littermates $(n$ $=8 / 8 ; p<0.001)$.

\section{DISCUSSION}

Significant decreases in serum calcium during light exposure were accompanied by decreased melatonin concentrations. When serum melatonin was sustained by CAP, the hypocalcemic response was prevented. We have previously (2) found that administration of melatonin prior to phototherapy also prevented hypocalcemia. These findings support the hypothesis that light-induced changes in serum calcium are the result of decreased serum melatonin.

In adult animals, the influence of light on melatonin synthesis is effected by impulses originating in the retina and routed via the accessory optic tract to the superior sympathetic ganglion, where the transmission of $\beta$-adrenergic impulses to the pineal is 
modulated. Increased $\beta$-adrenergic stimulation enhances the activity of $n$-acetyltransferase, an enzyme essential to the first step in the conversion of serotonin to melatonin; decreased stimulation has the opposite effect (8). In NBR $n$-acetyltransferase activity is inversely proportional to light exposure even after optic enucleation. This response is eliminated by opaque hoods (4). Hypothalamic-mediated gonadal responses to light in blinded animals and birds have also been reported $(9,10)$, and we found that optic enucleation did not prevent hypocalcemia during phototherapy in NBR (2). These demonstrations of direct transcranial photic effects are consistent with the prevention of hypocalcemia by occipital shielding and with the lack of calcium response to blue light, which has a low degree of cranial penetrance $(2,3,11)$. Table 1 shows that the scalp, calvarium, and dura of NBR transmit $4 \%$ of incident blue $(510 \mathrm{~nm})$ and green $(545 \mathrm{~nm})$ light; neither wavelength affected calcium at the energy level used. Yellow light $(640 \mathrm{~nm})$ showed a $6.9 \%$ transmittance and evoked a hypocalcemic response.

Isoproterenol, a $\beta$-agonist that induces $n$-acetyltransferase (8), substantially reduced the hypocalcemic effect of light exposure. The $\beta$-blocking agent propranolol, which suppresses $n$-acetyltransferase (8), reduced serum calcium in shaded rates unless exogenous melatonin was provided. The induction of hypocalcemia in rats by propranolol has been reported previously by other investigators (12).

We believe that the data herein presented support the hypoth- esis that hypocalcemia during phototherapy in NBR results from transcranial photic inhibition of melatonin synthesis.

\section{REFERENCES}

1. Romagnoli C, Polidore G, Cataldi L, Tortorolo G, Segni G 1979 Phototherapyinduced hypocalcemia. J Pediatr 94:815-816

2. Hakanson DO, Bergstrom WH 1981 Phototherapy-induced hypocalcemia in newborn rats: prevention by melatonin. Science 214:807-809

3. Sisson TRC 1977 Phototherapy of neonatal jaundice: effect on blood biorhythms. In: Castellani A (ed) Research in Photobiology. Plenum Press, New York, pp 431-434

4. Zweig M, Snyder SH, Axelrod J 1966 Evidence for a nonretinal pathway of light to the pineal gland of newborn rats. Proc Natl Acad Sci USA 56:515520

5. Bett JM, Fraser GP 1959 A rapid micro method for determining serum calcium. Clin Chim Acta 4:346-356

6. Penny R 1982 Melatonin excretion in normal males and females: increase during puberty. Metabolism 31:816-823

7. Penny R, Goebelsman U 1984 Effect of estradiol on plasma melatonin levels. J Endocrinol Invest 7:55-57

8. Axelrod J 1974 The pineal gland: a neurochemical transducer. Science 184:1341-1348

9. Benoit J 1964 The role of the eye and of the hypothalamus in the photostimulation of gonads in the duck. Ann NY Acad Sci 117:204-227

10. Genong WF, Shepherd MD, Wall JR, Van Brunt EE, Clegg MT 1963 Notes and Comments: penetration of light into the brain of mammals. Endocrinology 72:962-963

11. Wan S, Parrish JA, Anderson RR, Madden M 1981 Transmittance of nonionizing radiation in human tissues. Photochem Photobiol 34:679-681

12. Lund B, Hindberg I, Sorenson OH 1975 Hypocalcaemic effect of propranolol in rats. Horm Metab Res 7:176-180 